\title{
AN EXPERIMENT IN THE MOUND CITY (MO.) PUBLIC SCHOOLS IN ARITHMETIC TEACHING.
}

By Byron Cosby, State Normal School, Kirksville, Mo.

"From the standpoint of the child, the great waste in school comes from his inability to utilize, within the school, the experiences he gets outside, and to apply in daily life what he learns in school."-Dewey.

Mathematics is a difficult subject for pupil and teacher; requiring intense application and studied thought. It is hard to organize the everyday experiences into the definite statements for which mathematical thought calls. Lack of observation and previous experience prevent the learner from grasping all the elements of the question; causing him to base his argument upon incomplete premises. The problems in text-books may be well selected and well stated in general, yet abstruse and difficult to the individual. In the solution of a problem it is necessary to understand definitely what is given and what is required. The newer arithmetics have made advancement in the selection of problem material but offer only a step in the right direction. Even though the class of pupils, the environment, the text, mode of recitation, and the preparation of the teacher are strong factors, it cannot be overemphasized that it is very essential that the pupit be brought into an experimental relation to the problem material. Then instead of the recitation being a place for the teacher to find out whether or not an assigned task has been finished, and for the pupils to refer to answer books for results, it becomes the workshop where the pupil by essential and pertinent questions is logically and psychologically led to interpret the new problem in terms of his known ideas-that is, to translate the arithmetical question into his experiences.

The class exercise should be stressed. This calls for a strong personality in the teacher, as well as thorough knowledge of the subject. The knowledge and training of the teacher outside of books is a factor not to be eliminated-the teacher being the source of the pupil's knowledge, at least in directing where found. The teacher who has to depend upon "what the book says," cannot be in sympathy with individual growth, and is therefore inefficient. If teachers spent more time in home study upon actual life from the arithmetical side, and the methods of coordinating this material with arithmetical principles, along with a 
psy chological study of the child, the child could spend less time upon problems that are foreign to his experiences, and concentrate his energies upon known experiences with greater profit to himseif. All statements and answers in arithmetic should be given in clear-cut sentences. This is possible only when the child has previous knowledge of the subject-matter.

Believing that it is necessary that the pupil get his problem material from his own experiences and that the teacher develop with the pupils the problem material we made the following experiment in the Mound City (Mo.) public schools.

Our equipment was the same as may be found in, or easily obtained in most schools. The building at which the experiment was made consisted of eight grades; from primary to eighth grade inclusive, with a separate teacher for each grade. The library consisted of a few special books for the teachers' use, and several sets of arithmetics; a meager amount of apparatus of the elementary sort, and permission from the merchants, bankers, manufacturers, and other business men to visit their plants. at our pleasure.

In order to understand the nature of our problem material it may not be misleading to give examples of material that we did not use, as the following which was found in one of the presentday texts:

In Book I.

I. I have a flower bed containing 64 square feet. How long is it? (page 163)

2. How long in feet is a square yard? (page 154)

3. If each acre produces 28 bushels of wheat, what does a farmer get from 48 acres? (page 100)

4. Three boys bought a melon for fif teen cents. What shall each boy pay? (page 34)

In Book II.

1. Do you know what .528 feet means? (page 157)

2. I bought four loads of cos1. The weights were as follows: 4.08 tons, 3.92 tons, 36 tons, 5.01 tons. How much coal did I buy? (page 93)

3. Find the cost of $5 / 6$ dozen oranges at twenty-five cents. (page 66)

Are these problems real or artificial? Do they mean anything to you?

In Book III.

Two four inch spheres are dropped into a pail eves full of water and holding 864 cubic inches. How many cubic inches are displaced? (page 230)

What does this problem mean to a boy who has not experienced any of the problems in specific gravity? Experiment will not verify the problem. Try experiment with lead balls, and then with cork or wood. These examples might be multiplied, and though these particular problems may be corrected in later editions, the books are still full of problems that are false in problem material, poorly stated or foreign to the learner's experience. 
Other series of books present like weaknesses. The books furnish answers to the problems thus presenting a phase of life not actually found. Practically all of the books teach subtraction in one way and the business man insists upon changing money in a different way.

In order to get interest, effort, beauty, and practicality-the real reasons for studying arithmetic-the material learned at school should add to our resources either as usable and useful facts, or in power gained to observe the relation, and again the ability to associate facts that are pleasant to study, develop our æsthetic nature, or give us a greater advantage in control of conditions that assert themselves in everyday life. The recitation can in a large manner decide the after use of the subject. If the criticism that arithmetic is little used after it is learned at school is just, it may be removed by adequate preparation of the teacher, by change of method, and subject content. The recitation must coördinate with outside experiences, and teachers should know the problems of the farm, of the flouring mill, grist mill, canning factory, of the blacksmith, carpenter, of printing, banking, merchandising, of the elevator, of the railroad, the ice plant, the shoe factory, the electric light plant, the scoring of corn, the testing of gasoline, and similar problems in order to get the greatest development of the pupils.

The elementary grades were led to make simple measurements and observations, to state as definitely as possible, and to draw their own conclusions, from the following data collected by them under the immediate supervision of teacher or principal. The number of trees in the school yard, the number of bricks in the length and breadth of the walk, number of houses in a block, number of steps between various points in the room and yard, counting scores in games, lists of number of articles in stores, and other counting or combining problems. As the grades advanced the material was worked over in a different manner. The percentage of the number of boys or girls of all the pupils in school, number of trees that are oak or elm, what fraction of all the stores are dry-goods or drug stores, use of the number system of the streets for percentage, decimals and graph work, also using the range and township lines for location work leading to geography work in longitude and latitude, furnished problem material that is worth while. From township and range the "section" with its six hundred and forty acres and subdivisions gave the most interesting and practical problems especially as at different times the 
"section" was walked over by pupils and teacher. The amount of the exports of corn and garden products from the city, the import of food and other commodities with problems of freight and express charges, the production of berry, fruit or cereal crop, the rate of work in canning factory, the capacity of the flouring mill for week or month when the daily capacity is known, the initial cost of the plant, the cost of operation, value received for manufactured articles, furnished material that is new and real when gathered by the pupils with the help of the teacher.

The advanced grades found more in proportion in the problems of machines. The lever was easily understood by the average boy from his experience with the "evener," the balance arm on scales, and drawbar, and teeter board, and other elementary machines. The lever has a real interest to a live boy if he can use the idea in his work or play or again in proportion make use of the simple exercise of finding the height of objects or in measuring inaccessible distances by using similar triangles. Solving the similar triangle or lever problem by drawing to scale will mean more than the rule that "the product of the means divided by the given extreme equals the required extreme."

Instead of taking up the problems in excavations, lumber measure, wall paper and kindred problems as found in text-books the pupil had a better idea after studying the plan, or "blue print," of a building that was being erected near the school, and from the actual problems the pupils computed the number of cubic yards (loads) of soil rock that had to be removed for the basement, the amount of stone, brick, and concrete required for the foundation, the amount of lumber, glass, shingles, sand and cement for plaster, nails, and other material that was used. These problems were not all worked out at once, but as the building was being built, and after frequent visits and much actual measuring by the pupils. These problems were of a decided worth, because the pupil had the opportunity to utilize and expand facts that he had assimilated and furnished himself. This kind of problem eliminates unreasonable data that tends to warp the judgment and has a tendency to add to the pupil's knowledge of practical things. Also problems upon the amount of ammonium chloride used in producing a ton of ice, the amount of coal needed to light the city for a month, the amount of precipitation in the district, the flow of the river, the value of the advertising in an issue of the local paper, a study of bank paper, not only enabled the pupil to learn to "figure" but helped him to see "why." Many other lines of thought as found in our city were carried out. 
As to results his experiences in gathering problem material enabled the pupil to adjust his new material into its proper relation to the old, to recognize in later problems the arithmetical principle underlying the problem, and gave an incentive for attacking the problem. He could "see" what was given and what he was to find.

The problem being interpreted the solution was easy. This was not "story telling," play, or laboratory method, but life. Each child has a right to individual selection. Each uses his eyes, ears, and hands. His measuring and observing gave him clearer concepts, enabling him to distinguish early length, area, and volume, together with many other statements. The eighth grade boy or girl who spent one half day in a bank or with a corporation under his teacher and an intelligent clerk knew far more about stocks, bonds, and promissory notes and checks than he could have known from all of his work in the class room. This working knowledge of a few practical applications developed the power to apply, and convinced the pupil how indispensable arithmetical thinking is to everyday life. A few application problems that were real "thoroughly mastered in form and spirit" were worth many times the number simply memorized as facts.

In the Mound City (Mo.) public schools we tried to carry out the plan outlined above. Frequent excursions in and out of school hours were taken. The excursion to the grocery store was rich in problems for the third and fourth grades. The bank visit, with a study of notes, drafts and checks, rate of exchange, dividends and other banking terms with an explanation of savings, state, private and national banks had a tendency to make the pupil appreciative not only of school but of business in general.

A resume: The real problems are:

1. To get the teacher to understand that arithmetic teaching need not be composed of simply text-book material.

2 . To select problems that are valuable as types. This develops mathematical principles that are usable though abstract.

3. How to teach the pupil to see arithmetic in life, adaptation of arithmetical principles to his observations. It leads to accuracy in conception, expression, manipulation and economy.

4. "The problem of incentives is solved; the reason "why" is understood.

5. To determine by use in the school room the adaptability for elementary work. The problem gathering idea develops the initiative and furnishes individual strength.

6. To educate the pubiic that school work can be accomplished outside of the school room as well as in the class-room.

7. To economize in the use of time. Pupils are more familiar with the details of the problems and hence are more accurate.

8. To enable the pupil to grow upon the material that he understands, and to atilize within the school, the experiences he gets outside, and to apply in daily life what he learns in school.

The above plan was worth while; it increased the per cent of enrollment, per cent of attendance and punctuality and made a 
closer bond of sympathy and help between the teacher on one hand and the pupil and patron on the other hand. At the close of the year the pupils had gained more individual power, were able to use their knowledge, to use in vocation the power thus gained, and to feel that their school work had at least utility value for them. The teachers worked hard and were contented, the patrons were pleased; and to some extent there was carried out the meaning of education-to be a help to usefulness and happiness.

\section{NEW PHYSICAL AND CHEMICAL TABLES.}

The preparation of a new edition of the standard work now known as Landolt \& Börnstein's "Physikalisch-chemische Tabellen" has been undertaken by Dr. Börnstein of Berlin and Dr. Roth of Greifswald. These two writers have set an admirable example in addressing a circular to men of science and scientific institutions throughout the world inviting suggestions as to additions, omissions, or other changes likely to increase the value of the work. Such suggestions shonld be sent either to Geh. Reg.-Rat Prof. Dr. R. Börnstein, Landhausstrasse 10, Wilmersdorf bei Berlin, or to Prof. Dr. W. A. Roth, Karlstrasse 8, Greifswald.

\section{GLACIAL NATIONAL PARK.}

\section{Map Now Being Engraved by United States Geological Survey.}

The United States Geological Survey has in process of engraving a fine topographic map of the new Glacier National Park. This map will be used in the administration of the park by the Interior Department and will also be available for distribution to the public.

This splendid people's playground, the youngest of our national parks, covers nearly a million acres in northwestern Montana just south of the Canadian line and includes the Lewis and Livingston mountain ranges, which constitute the northern Continental Divide. Throughout the area hundreds of majestic peaks rise $8,000,9,000$, or 10,000 feet above sea level, alternating with sheer-walled canyons $1,000,2,000$, and even 3,000 feet in depth, at the bottom of which dash glacial torrents. More than sixty glaciers may be found in the park, some of them several miles in area. The map shows also many lakes, large and small, nestling in the old glacier-scoured basins. The glaciers of the park are but small remnants of the mighty continental glacier which, during the Ice Age, mantled the northern portion of the American continent, yet some of them are sufficiently stupendous to challenge the daring and ability of the hardiest alpine climbers. and explorers. The park is described by the federal topographers as a place of wondrous beauty, perhaps one of the most beantiful and magnificent mountain regions in the world. As long as a dozen years ago John Muir described this portion of Montana as one of the most favored spots of the continent, where men might almost find the springs of renewed life. At least, he said that a season's sojourn in this region should add ten years to the traveler's earthly sojourn. 